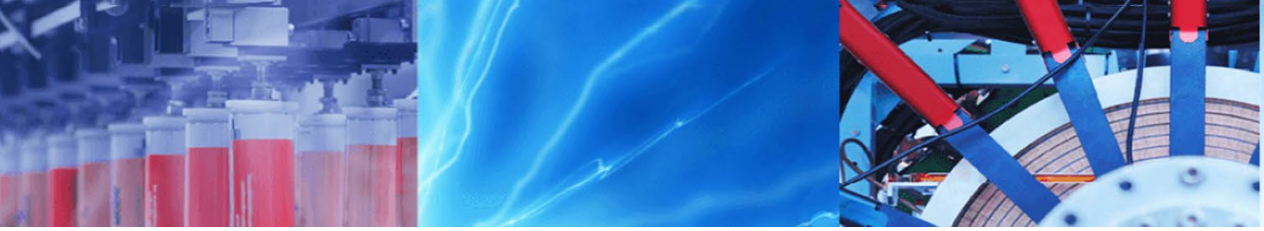

Review Paper

\title{
An overview of additive manufacturing technologies for musical wind instruments
}

\author{
Ajith Damodaran ${ }^{1}$ (I) M. Sugavaneswaran ${ }^{2} \cdot$ Larry Lessard $^{3}$
}

Received: 18 June 2020 / Accepted: 6 January 2021 / Published online: 20 January 2021

(c) The Author(s) 2021 OPEN

\begin{abstract}
This paper aimed to provide a foundation database for understanding the important applications of the different additive manufacturing (AM) technologies for musical wind instruments. A systematic review methodology was adopted in this study. The different AM techniques, materials used, the technical features, and processing parameters uniquely related to wind instruments were discussed. Selected heterogeneous applications demonstrate how AM techniques are being exploited in the innovation, improvement in aesthetics of the existing wind instruments, understanding the ancient music, and personalization with its capability to tune specific instrument design parameters for professional musicians.
\end{abstract}

Keywords Additive manufacturing $\cdot$ Wind musical instruments $\cdot$ Flute $\cdot 3 \mathrm{D}$ printing

\section{Introduction}

ISO/ASTM 52,900-15 defines additive manufacturing (AM) as"the process of joining materials to make parts from 3D model data, usually layer upon layer, as opposed to subtractive manufacturing methodologies". First introduced in the 1980s to serve the highly specialized needs of model making, AM combined with advanced computer aided design (CAD) emerged as a versatile technology platform for product development [1]. The terms 'layered manufacturing and 'rapid manufacturing' are also generally seen as synonymous with AM. Another popular term that is often used is '3D Printing' which actually refers to a specific AM technology. AM technologies are now widely adopted by the designers to make functional end use parts. Compared to traditional manufacturing methods such as machining, molding and forming, AM permits the development of a model with complex geometries easily. Since the models can be built without the need of expensive molds, process planning and skilled labour, AM permits design flexibility [2].

Due to these design freedoms, there is a paradigm shift in the manufacturing process and AM enables in converting non tangible digital data into a value-added product within a short time. Additionally, advancement in machine development has reduced AM machine cost which results in technology accessible to homes, school laboratories and individuals [3]. Wohler's report suggests that the demand for AM machines is increasing globally [4]. In the last two decades, AM has evolved significantly and is capable of producing fully functional end use parts. AM has been established in various engineering applications like biomedical, aerospace, defence, and construction $[5,6]$. Artists and designers working in conservation, jewelery, sporting goods, leisure products and musical instruments have also benefited with the exponential growth of AM in the last decade and are evident in the literature [7-9]. The major benefit in AM technologies is due its inherent capability of innovation and customization opportunities in the

\footnotetext{
$\triangle$ Ajith Damodaran, ajidamodaran@gmail.com | 'Department of Mechanical Engineering, Easwari Engineering College, Chennai 600089, India. ${ }^{2}$ School of Mechanical Engineering, VIT University, Vellore, India. ${ }^{3}$ Department of Mechanical Engineering, McGill University, Montreal, Canada.
} 
new product development [10]. However, among the various applications, the prospects of AM in musical instrument research are often overlooked. Recent studies show that $\mathrm{AM}$ technologies have a bright future in musical wind instrument development $[11,12]$. This paper presents a foundation database for understanding the potentials and challenges by focussing on the different AM technologies and materials innovation that could benefit musical wind instruments.

\section{Background}

Among the various musical instruments, namely percussion instruments (sound produced by a stretched membrane over an enclosed cavity), e.g., drums; stringed instruments (stretched strings are allowed to vibrate over a sound board), e.g., guitar, violin; and wind instruments (sound produced by blowing air through a mouthpiece in to a hollow chamber), e.g., flutes; the wind instruments rely more on the geometry of the instrument [13]. For example, the pitch of the instrument is proportional to the length of the tube. Experimentation with futuristic shapes, personalization by varying the internal chamber dimensions of the mouthpiece have already reported in $[14,15]$.

The AM process plays a vital role in the development of these shapes for quality sound in a musical instrument. However, there are limitations in terms of required characteristics in materials processed through AM techniques. For example, one significant material characteristic that impacts the sound is resistance to abrasion (hardness) and stiffness which is related to the elastic modulus. In general, a quality instrument should be dimensionally stable withstanding any low-level external impact (such as that due to accidentally dropping the instrument). Such impacts can damage the shape of the part and affect sound quality [16]. Hence the ideal material for a musical instrument should be able to resist impact, shock and scratching. Finally, the material should not cause any health issues to the players and hence the materials chemical composition is also critical.

Musical instrument research is definitely an interdisciplinary field which involves physics of instruments, materials science, acoustics, manufacturing methods and study of ancient instruments and the development of new instruments. Traditional instrument design relies on the skill of the craftsman and the quality of the raw materials used. Furthermore, the development of an optimal instrument is the result of numerous design iterations and hence the traditional method is to develop a number of prototypes before the actual instrument is made. The development of the instrument is often a time-consuming process and requires custom-made tools and fixtures and thus results in high cost of the instrument. Additionally, process planning and tool development restricts the traditional manufacturing process for rapid response to change in design. In this regard, AM could provide substantial ease of manufacturing and reduction of costs. AM in combination with CAD (Computer-Aided Design), and CFD (Computational Fluid Dynamics) tools helps researchers, instrument builders and players to experiment with unconventional designs, understand the ancient music instrument and provides an opportunity for personalization of the instrument design parameters. This would otherwise impossible with traditional manufacturing methods [11]. AM also offers material and energy conservation, especially for fabricating curved parts compared to subtractive techniques. Additionally, AM is complementary with the reverse engineering tools and assists in the restoration or repair of instrument parts. Furthermore, AM technologies are suitable for low volume batch production and could meet ever-changing needs of the customer [17].

Recent advancement in process control and postprocessing strategies has resulted in the availability of material with necessary characteristics for musical instruments. Internet searches have also revealed various startups (https://www.syos.co/en) where the user can order customized music instruments with desired material and sound characteristics. It is evident that a potential research interest among researchers and enthusiastic individuals on diverse applications of AM for musical instruments and more specifically wind instruments [11]. In order to leverage the AM's potential, it is necessary to have an understanding of the manufacturing process, different technologies involved, materials used, material properties such as mechanical, chemical, and biocompatibility properties. In this regard, the present overview focusses to assist researchers, curators, instrument builders and the musicians concerned with innovation functionality, cost and aesthetics of the instrument.

\section{Methods}

A systematic literature search was performed [18]. The initial search contained variations or combinations of the following terms and keywords: three-dimensional printing; additive manufacturing. These terms were combined with a list of terms pertinent to wind instruments, which included the following: musical instruments; wind instruments; flute; mouthpiece; clarinet (Table 3). Inclusion/exclusion criteria and keywords were defined to select items in the literature by assuring the relevance of the article to the research in focus. The identified studies were evaluated on their suitability for data-extraction first by abstract and eventually by reading the full text. 
Studies that met the following criteria for data extraction were included: the studies (i) studies that investigated AM technology in a musical instrument context (ii) studies that provided detailed presentation of the methods adopted and quality of the results. The data were collected within the period from 2011 to the third quarter of 2020.

The structure of the paper is as follows: First, an introduction about AM is presented, describing what it is, its main advantages over traditional manufacturing methods. In the second section the need of AM process in the design and development of musical instruments and the required material characteristic required for musical wind instruments is reported. The methodology adopted for literature search is described in section three. A summary of results and categories of application are shown in the results section. The fourth section discusses the different AM technologies; technical features, materials used, and process parameters pertinent to the development of wind instruments. The applications of AM technologies for wind instruments are categorically discussed. Further, future directions of research are highlighted and the paper ends with the conclusion and limitations of the present study.

\section{Results}

The literature search method resulted in 14 key cited papers and 2 conference publications that contributed to the scope of the present work. An extract of the major search highlights is shown in Table 1. These categories and recurring concepts helped the authors to comprehend the information from each paper. The different AM technologies and AM applications for wind instruments are discussed below.

\subsection{Additive manufacturing technologies}

All the commercially available AM technologies have been investigated in the development of music instruments. The different AM processes employed in the selected 16 contributions were classified as per the ASTM 52,900-15 standard AM principles terminology. The different AM technologies can be grouped into (i) material extrusion (fused deposition modelling, FDM), (ii) powder bed fusion (selective laser sintering, SLS; electron beam melting, EBM), (iii) Vat polymerization (stereolithography, SLA; digital light synthesis, DLP; continuous liquid interface production, CLIP) and (iv) material jetting (Polyjet) [3]. The data resulting from this categorization are shown in Fig. 1. The description of these technologies, materials used and the challenges are discussed briefly. In Table $2 \mathrm{com}$ monly used AM methods applied in the wind instrument research, mentioned above are gathered with schematic details, the materials used, advantages and drawbacks, etc. A detailed description of the different AM process is found in [19].

\subsubsection{Material extrusion}

4.1.1.1 Fused deposition modelling (FDM) In this method, a thermoplastic wire material is heated (resistance heating) and the semi-molten material is deposited layer by layer via nozzle on a platform as per CAD model. This layering in different raster orientation gives FDM parts anisotropic properties. Classical flutes, whistle and horns are a few of the wind instruments that have been developed

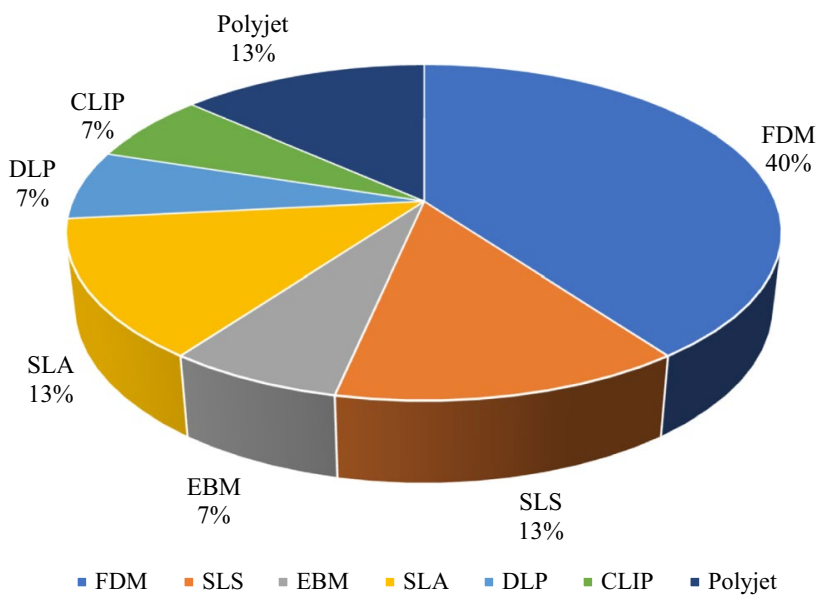

Fig. 1 Additive manufacturing technology of the 16 selected contributions

Table 1 Extract from the selected 16 literature survey

\begin{tabular}{|c|c|c|c|c|c|}
\hline Reference & {$[22,25,28,30-34]$} & {$[35,36]$} & {$[21,38]$} & {$[17,39]$} & {$[20,26]$} \\
\hline Category of application & $\begin{array}{l}\text { Reconstruction of } \\
\text { ancient instruments }\end{array}$ & $\begin{array}{l}\text { Research and develop- } \\
\text { ment }\end{array}$ & Education and training & Personalization & Innovation \\
\hline AM principles & $\begin{array}{l}\text { Material jetting/Material } \\
\text { extrusion/Vat polym- } \\
\text { erization }\end{array}$ & Material extrusion & Material extrusion & $\begin{array}{l}\text { Material jetting/ } \\
\text { Material extru- } \\
\text { sion }\end{array}$ & $\begin{array}{l}\text { Powder bed } \\
\text { fusion/Vat } \\
\text { polymeriza- } \\
\text { tion }\end{array}$ \\
\hline
\end{tabular}




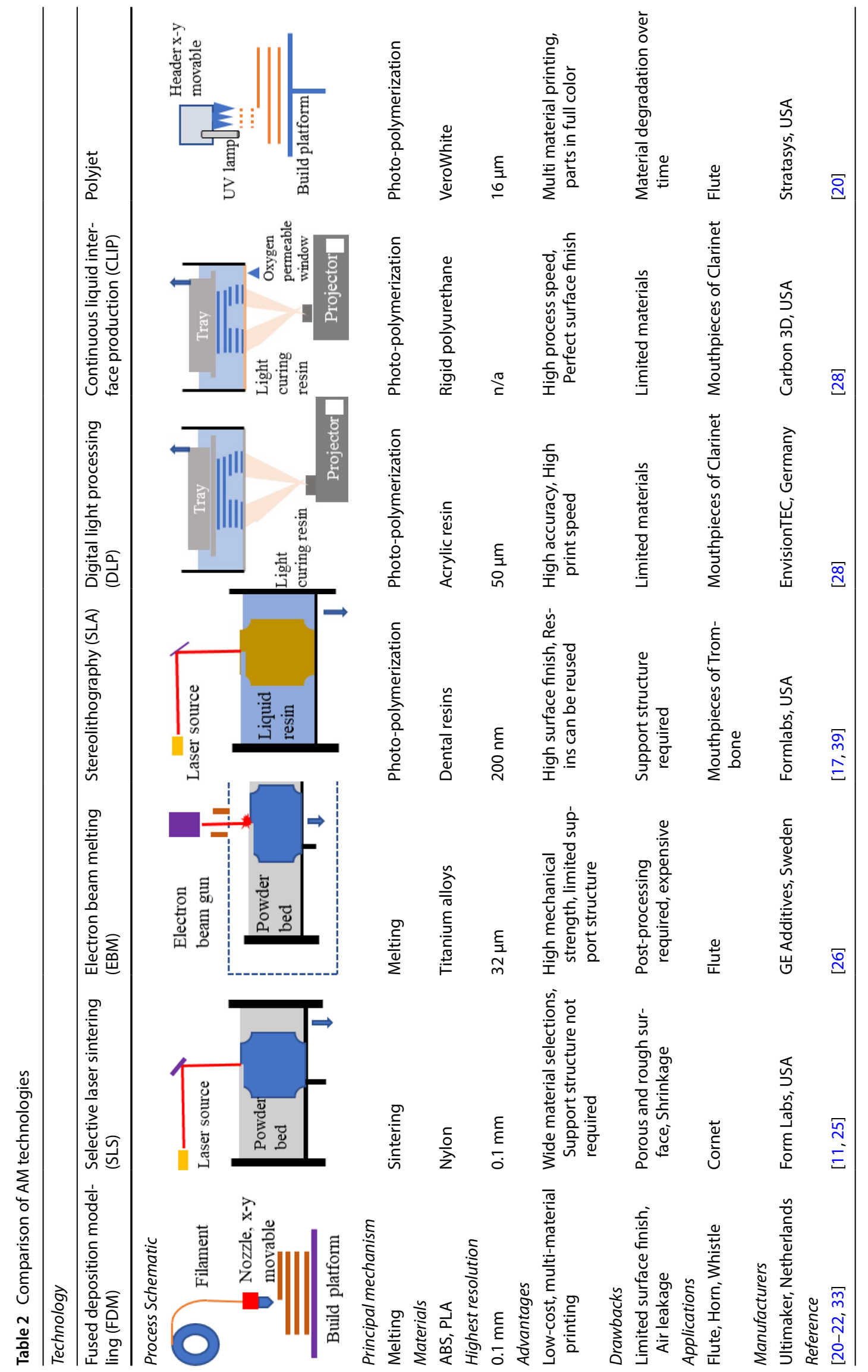


using the FDM process [20-22]. Simplicity and affordability of the equipment, availability of raw materials made FDM technology a popular choice for developing prototypes for research and functional end use parts.

FDM enables a wide range of printing materials including additives. The most common materials used were PLA (polylactic acid) and ABS (acrylonitrile butadiene styrene). Marin et al. [22] exploited the use of PLA (standard black color), the combination of PLA and metallic copper (80\%PLA and 20\% copper), PLA and Bronze, (80\%PLA and $20 \%$ copper), and pure ABS (yellow color) for replicating an ancient horn. Prototypes developed from ABS suffered a few setbacks; namely lack of proper adhesion in the first layer and required a heated bed for printing to prevent warpage. The main advantage of PLA is that it permits the addition of an additive into the polymer and also does not emit any toxic gases while heating. The prototypes developed from ABS and PLA are inferior due to the soft nature of plastics and also they absorbed acoustic waves, which thus resulted in loss of harmonics. They concluded that the combination of PLA and copper have the sound characteristics that match traditional horn made from brass.

Even if the advantages of FDM technology are clear, it is important to underline some limitations as well as: layer resolution, the stair effect on the surface, component anisotropy, the requirement of a support structure, low strength in direction transverse to layer by layer deposition and so on. This performance majorly depends on processing parameters such as layer thickness, air gap and raster orientation [23]. For instance, in fabricating the FDM flute, due to low surface resolution, the surface of the holes and the printed pads was relatively rough and the air was not blocked properly. Wind instruments demand that components to be airtight otherwise air punches out form the instrument. Hence the secondary step of sealing of the printed part is often required if the thickness of the printed part is relatively thin [20]. Further, the printing parameter called "infill" in FDM can affect functionality (due to air pressure leakage when the value of infill was low) as shown in the case of the printed whistle [21].

\subsubsection{Powder bed fusion}

Powder bed fusion is an AM process in which thermal energy provided from the sources (laser or an electron beam) selectively fuses the region of the powder bed. Selective laser sintering (SLS) and electron beam machining (EBM) are reported in this category.

4.1.2.1 Selective laser sintering (SLS) Selective laser sintering (SLS) works by a $\mathrm{Co}_{2}$ or $\mathrm{Nd}$ : YAG laser selectively sinters the contours of a cross section corresponding to the CAD model. It consists of thin layers of very fine pow- ders, which spread and closely packed on a platform. The powder is heated below the melting point. The piston-controlled platform and the succeeding layer is patterned subsequently on the powder bed is moved downward. Un-sintered powder remains in place as support. The printing parameters like laser speed, layer thickness, scanning speed, powder bed temperature, orientation of parts that contributed to the strength of the part were discussed elsewhere [1, 24].

Earlier studies reported by Savan and Simian showed SLS printed instruments (ancient cornett) using nylon material have exhibited porous and rough structure [25]. Hence post processing operations are required to seal the bore and to improve the ease of playing. However, the post-processing operations (sealing with a coat of varnish) resulted in slight distortion in the accuracy as compared to that of the cornet from museum collections. In reference [11] a saxophone (Fig. 2) using the SLS technique was reported. Compared to traditional saxophone the weight of the additive-manufactured instrument is reduced by $25 \%$. However, due to the low stiffness of nylon material, the saxophone suffered from air leakage and uneven spring pressure. Further, fatigue issues can arise, for example, in the case of thermoplastics such as ABS, where the stiffness changes are noticeable with varying temperature more than with other materials. Apart from wind instruments, SLS technique is also used in development of string instruments, guitar. However, except for the body, other

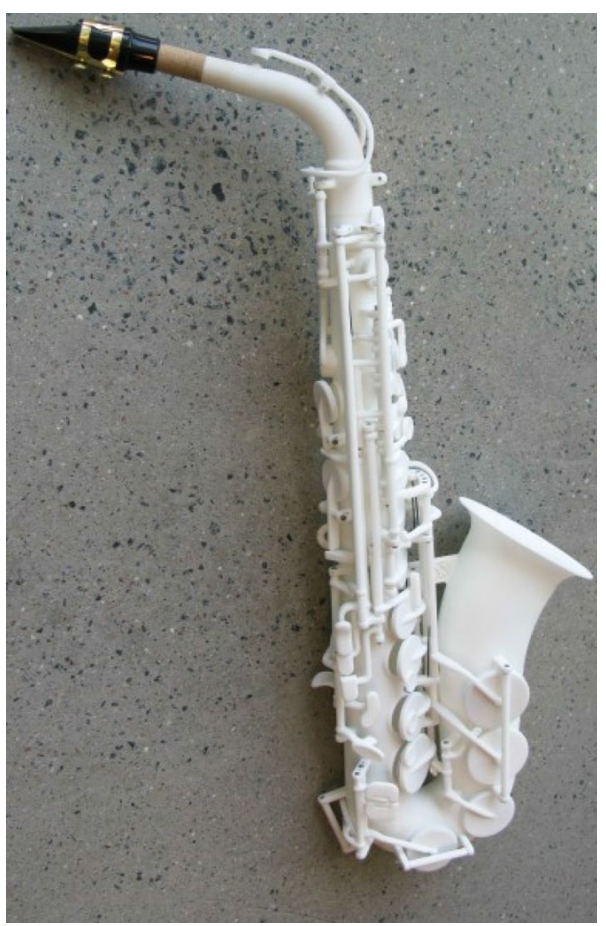

Fig. 2 Additive-manufactured Saxophone. Source [11] 
parts like the neck are made with conventional manufacturing technique.

4.1.2.2 Electron beam melting (EBM) In the EBM process instead of a laser beam, a high-power electron beam melts the powder layer according to the cross section of the CAD model. In order to avoid deflection of gas molecules, a vacuum environment is needed. Even though wind instruments are made from a wide range of materials, the progress in AM technologies has helped researchers to investigate the prospects of the flute made from titanium alloys (Fig. 3).

Kolomiets et al. [26] demonstrated the functionality of the additive-manufactured flute rather than experimenting with futuristic shapes. Ti-6Al-4 V powder is used and the various design cases of flute were printed on an Arcam EBM A2X machine from GE Additives. Superior mechanical properties like ductility and strength, corrosion and fatigue resistance, minimal residual stress in the manufactured parts, biocompatibility and non-toxicity of the material are the main advantages of the EBM printed parts. Further, for tube-like geometries EBM process requires limited support structures. Despite the key benefits with titaniumAM flute, it suffered from specific challenges in polishing the surface and holes. They reported that removal of partially melted powder particles presented on the surface of the flute possesses a serious challenge. 200-grit sandpaper was used in the initial stage and the final finishing with a Dremel (high-speed handheld rotary tool). The inner surface of the flute was smoothened using a drill. Specifically, the surface roughness was reduced from Ra value 7.457 to 5.032 microns. Further, for the sound testing purpose, the joints were sealed with an acrylic sealant.

The potential of three-dimensional lattice structure has been investigated in that study. The development of lattice patterns is difficult in conventional manufacturing and in the case of a metal flute this has helped in reducing the material consumption and enhancing the aesthetics. Thus, titanium-AM illustrates innovative, durable, light weight, personalized designs and optimal wall thickness for the desired acoustic properties. They concluded that the sound produced by the titanium-AM flute is 'richer' than that of a commercially available Yamaha's polymer flute.

\subsubsection{Vat polymerization}

4.1.3.1 Stereolithography (SLA) In SLA systems, coherent light sources are used to induce polymerization and cross linking of the photopolymer resin. An SLA machine usually consists of a built platform which is immersed in a bath of liquid resin (acrylic or epoxy resins). The model is built in layers by scanning and curing the photopolymer resin with the laser beam. After the first layer is built on the platform, the platform is lowered to the same depth below the resin surface, enough for another layer of resin to be swept across and scanned. The liquid resins do not provide any support for overhanging parts and hence additional support structures have to be incorporated [7].

A trombone mouthpiece reported in [17] was developed using SLA. They focussed on the different AM technologies to investigate the change in geometry, material on the sound characteristics of the instrument. Different mouthpiece models are produced using Formlabs Form 2 machines and a non-toxic, biocompatible dental resin. It is believed that external high-quality finishing; overall accuracy level and affordable prices for small parts are the main advantages of SLA technique. As mentioned, the support structure is also made with the final object material, SLA techniques suffer difficulty in removing the support structure by the washing process. As the inner chamber of the mouthpiece should be smooth, dimensions have to be carefully finalized in order to avoid unremoved support structure. Further, to improve the strength and to avoid any deformation of the mouthpiece post-processing operation using UV ray was performed. These post-processing operations resulted in changes in aesthetics of the mouthpiece. Specifically, the color changed from yellow to orange. They concluded that SLA technique provides high customization capabilities, viable for low volume production and capable of producing similar sound to that of instrument parts made from metal mouthpiece.

4.1.3.2 Digital light processing (DLP) Digital light processing (DLP) is similar to SLA technique, DLP uses light to selectively cross link a photopolymer resin in a layerby-layer fashion. As opposed to SLA, each layer is not exposed point-by-point but all at once with a selectively masked light source. Since the whole layer of the structure is produced in one exposure step the build time is lower compared to SLA. It has a significant advantage when the cross-sectional area of a part is larger [27]. In reference [28] Clarinet mouthpieces are manufactured using EnvisionTEC printers with an acrylic based photopolymer resin (R11). Two mouthpieces and a barrel was printed in a single build and it took around $13 \mathrm{~h}$ and $40 \mathrm{~min}$. The layer thickness was 50 microns in $\mathrm{z}$ direction and 32 microns in
Fig. 3 Additive-manufactured titanium flute. Source [26]

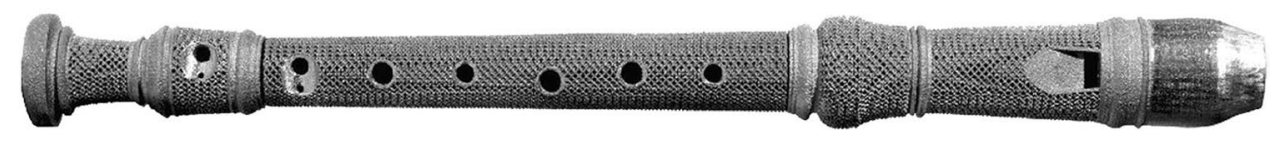


$x-y$ direction. This process resulted in mouthpieces with smooth surface finish. However, the sound produced by the mouthpiece has a mixed response from the professional musicians.

\subsubsection{Continuous liquid interface production (CLIP) CLIP} is a variety of VAT polymerization AM, which uses an oxygen-permeable window to inhibit polymerization at the surface close to the UV source. This process is commercialized by the company Carbon 3D [1]. In reference [28], Clarinet mouthpieces are manufactured using CLIP process. The material used was rigid polyurethane. A total of 6 mouthpieces and 1 bell were built in $3 \mathrm{~h}$, and the process was much faster than that of other AM processes. Compared to other AM techniques, the process is quicker, with higher resolution and better surface finish. The sound characteristics were also favoured by professional musicians and scored marginally ahead compared to all other AM techniques. Recent research has shown that CLIP allows production of objects from hard to elastic polymers [27].

\subsubsection{Materials jetting}

4.1.4.1 Polyjet Polyjet machine consists of an inkjet head with several hundred nozzles swept along the $x$-axis and in the process ejects small droplets of the photopolymer. After each layer is deposited, a UV-lamp flash cures the fresh layer and the process is repeated. The main advantage of this process is that it allows the use of multiple materials with variable physical properties [29]. Due to pixel to print control as opposed to vat resin method discussed in Sect. 4.1.3, it is possible to print three-dimensional multilaterals or multicolor structures. This property is very much useful for the design of a flute (Fig. 4) allowing different mechanical properties to the printed object in order to create soft areas and rigid areas [20].

Amit Zoran's flute design was based on a standard concert flute. Polyjet technique is used to come up with an

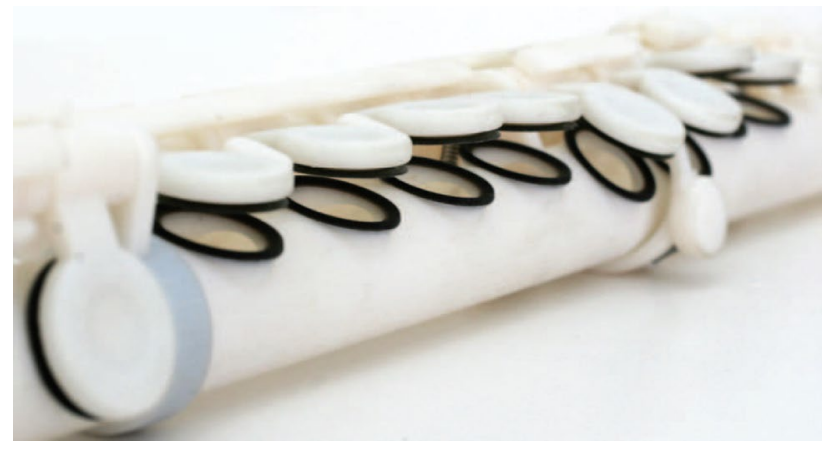

Fig. 4 Additive-manufactured flute. Source [20] optimal flute. The Objet Connex system (printer) allowed the rubber seals for all the keys as an integral part of the keys. It is reported that Polyjet printed flute exhibited better end use capabilities. It is believed that reduction in printing time, airtight components and resemblance of the sound to that of traditional instruments are the main advantages of this material jetting technique. However, the major disadvantage is that degradation of the strength and dimensional stability over time. The UV cured material can result in bending failure with time due to material aging. In the future, if this material degradation issue can be resolved, these technologies will become of greater interest, as they produce parts with excellent surface finish. More research is needed into the extent of cure of polyjet parts, the effects of different environmental conditions on material degradation and building orientation on anisotropy [11].

Cortell and Howell investigated different AM techniques to come up with the optimal mouthpiece for an ancient Clarinet [28]. An Objet 500 machine using VeroWhite material (acrylic based photopolymer) was used to print the mouthpiece. They reported that mouthpieces printed using Polyjet achieved a layer height of 16 microns in the $z$ direction and $x-y$ is 42 microns. Four model print heads and four support print heads are incorporated. The support material is a gel-like substance and removed during the post processing using a water jet. Polyjet technique is suitable for printing objects which requires accurate detailing and smooth surface finish. They concluded that mouthpieces made from Polyjet have something appealing in the sound.

From the interdisciplinary literature survey, all the reported AM techniques for wind instruments were discussed. In general, it can be noted that AM techniques have contributed significantly in musical wind instruments research, design and manufacturing. The major applications AM for wind instruments are explained below.

\subsection{Applications for musical wind instruments}

The important applications of AM that are pertinent to musical wind instruments are grouped into five categories: (i) restoration/repair of ancient instruments, (ii) research and development, (iii) education and training, (iv) personalization, and (v) innovation. Figure 5 shows the AM applications of the selected 16 contributions.

\subsubsection{Restoration of ancient instruments}

The accessibility of original instruments/ancient instruments that are confined to a specific piece for the players or common man is often difficult. Even if the instruments survive many of the parts are broken or missing and may 


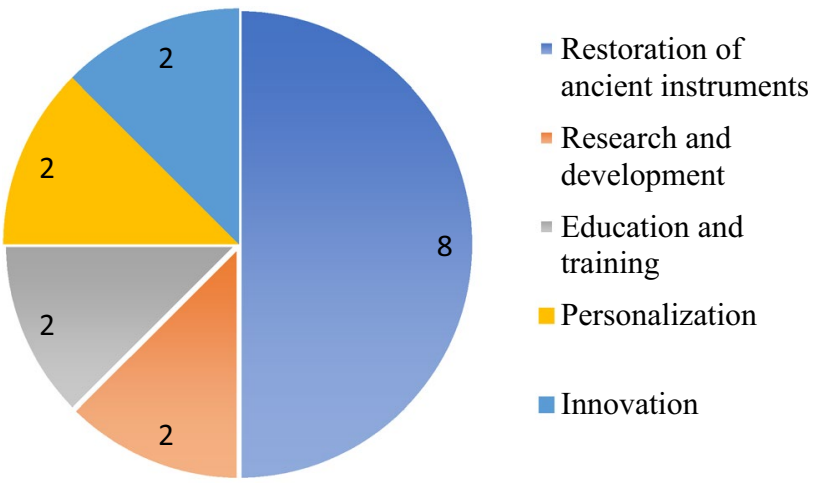

Fig. 5 Additive manufacturing applications of the selected 16 contributions

not be functional. Further some instruments are considered as precious and are kept in museums or private collections. In this regard, the potential benefit for individual musicians to create instruments or missing components using various $A M$ techniques are discussed in $[25,28]$. As a first step, the restoration starts with dimensional data collection from the existing or non-existing part. Researchers have adopted different methodologies for data collection. For example, the integration of computer tomography (CT) technique has been exploited in the restoration of an antique Saxophone mouthpiece and Greek Alus (wind instrument) [30-32]. The advantage of the CT technique is that it allows data collection without any object disassembly. Additive-manufactured mouthpieces supported the sound testing of the different design combinations and resulted in a playable Saxophone that possesses all unique parameters of the original version.

In another notable study, in order to facilitate the study of ancient Maya music, the potential of AM is investigated by Katz [33]. That study is aimed to create an interest in Mayan musical instruments for the general public. A globular flute from Guatemala (dated between 300 and $900 \mathrm{CE}$ ) is successfully recreated with the help of AM technique (Fig. 6). Data collection is carried out with the help of a DSLR (digital single-lens reflex) camera and battery powered LED light panels. The image-based modelling operations are carried out using Agisoft photoscan pro software. Editing and modelling of the resonance chamber is performed with Autodesk Maya software. The required $\mathrm{G}$ codes (used to control the machine movement) are generated using ReplicatorG software and globular flute is made using FDM technique (Flash Forge Creator Pro printer). Post-processing is carried out with the help of hand-held needle nose pliers to remove the support structures from the resonance chambers of flute. It is reported that 3D modelling of the embouchure hole presented a challenge as the position of the hole significantly affects

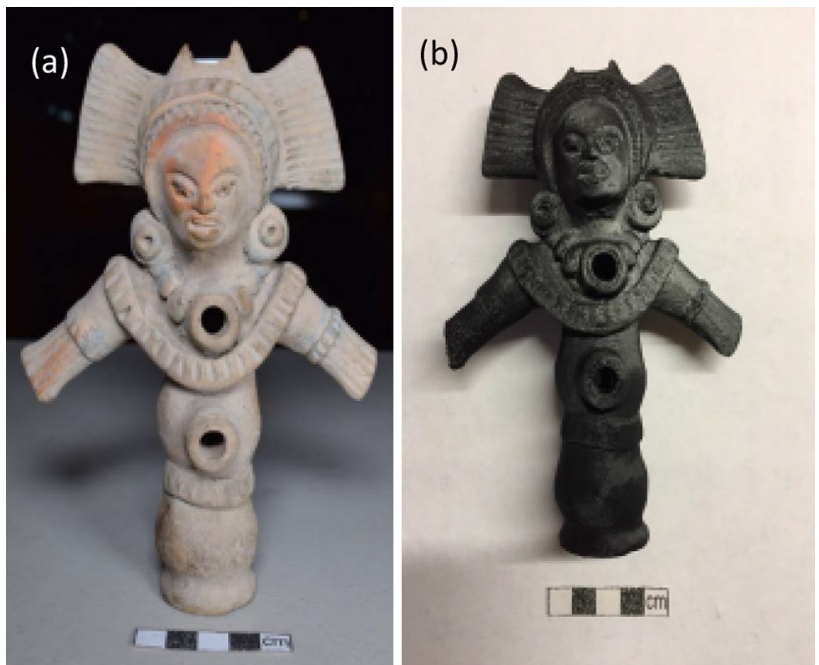

Fig. 6 Restoration of Globular Mayan flute a Original version b Additive-manufactured flute. modified form Source [33]

the sound produced. Another challenge is modelling the optimal size of the internal duct resonance chambers. Nevertheless, AM and CAD tools have helped making various trials of the flute by altering the shape of the hole in the digital model which would otherwise be very expensive with conventional manufacturing technique. Despite the challenges, AM-flute produced similar tones to that of the original version and the same is demonstrated with the help of a spectrogram. It is concluded that AM and CAD tools provided a better understanding of the technological attributes found in ancient Mayan instruments.

In reference [22] and [34], with the help of a 3D laser scanner for data collection, an ancient horn which is part of phonograph (sound recording device) and lyre (Ancient Greek instrument) were successfully recreated. They have concluded that AM along with CAD modelling and well-established reverse engineering methods helped in reconstructing the ancient horn both aesthetically and functionally, irrespective of the complexity of the geometry. The reader should note that the Phonograph and Lyre do not fall in the category of wind instruments; however, the objectives and methods are significant in covering the scope of the present study. A general framework in all the above reported restoration studies for instrument parts were presented in Fig. 7.

\subsubsection{Research and development}

From a research point of view, the ability to make completely new instruments is one of the important applications. Wind instruments, in particular, can produce entirely new classes of the instruments because the wind can be directed over shaped cavities that affect 
Fig. 7 General methodology for restoration of ancient instruments using additive manufacturing
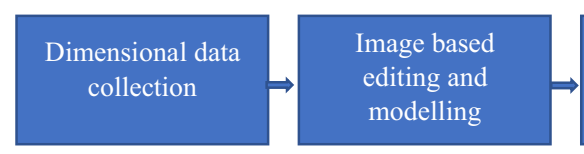

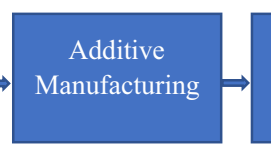

Sound

evaluation

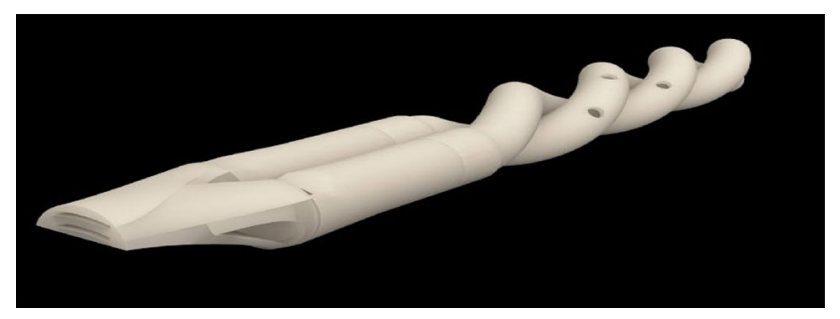

Fig. 8 3D model of a microtonal flute. Source [37]

the sound. In reference [35], researchers developed a tool called Printone, which allows conversion of any 3D shape into a functional wind instrument and their interface provides interactive sound simulation feedback to the user. The authors coined this type of wind instrument as "print-wind-instruments" in comparison with woodwind instruments. It was also said that by using their approach, "a novel wind instrument can be designed in about half an hour". The researchers aimed to recreate a predefined musical note using unconventional shapes. However, the significance of timbre (how the sound of one instrument differentiates from others even if both musical instruments play the same note) has not been investigated in these new instruments. If this new development is to be accepted in the music community, the influence on the timbre of the printed wind instruments needs to be further investigated. However, the significance of AM techniques in musical acoustics research was demonstrated.

In University of Wollongong, researchers investigated the potential of 3D modeling and AM to create customized flutes that can play music in a variety of microtonal scales [36]. In the field of microtonality, conventional musical instruments and manufacturing methods are inadequate to realize the abundance of theoretical tunings that musicians wish to investigate. A 3D model of a microtonal transverse flute was shown in Fig. 8 [37].

\subsubsection{Education and training}

AM can foster an early learning of the science of musical instruments, classification of musical instruments including the design aspects of how the instrument is producing sound. It is believed that seeing the transition of a 3D model into a real-world object helps in the understanding the physical characteristics of the object. Focusing on musical instruments, specific examples are: How the introduction of an additional finger hole implies in a wind instrument like recorder/flute? [38]. The prospects of changing the dimensions of a whistle (specifically the effect of the change in the radius of the whistle body and length and width of the mouthpiece) and its implications of the output sound are investigated by the researchers at Yamgatta University in Japan [21]. In that study, high school students designed a police whistle using 3D CAD, printed using FDM technique and examined the functionality. Among the various design parameters, the radius of the whistle has significantly affected the frequency. It is interesting to note that high school students could predict how the volume of air circulation in the whistle affected the frequency. They concluded that AM helped students in the practical understanding of musical instruments, threedimensional space, figures, machine control and materials.

Further the availability of simplified versions of modelling tools in the market like Microsoft 3D builder, Doodle 3D transform and Autodesk helps children to model and build their own innovative models. Apart from musical instruments development, AM also helped in the context of music learning and teaching through low budget devices [38].

\subsubsection{Personalization}

There has been a constant trend throughout the history of music performance in modifying acoustic musical instruments and using them as per the player needs. For example, among saxophone players, there is an everlasting quest for finding the most suitable mouthpiece, as it

Fig. 9 Innovative musical wind instrument designs. (Source [20])
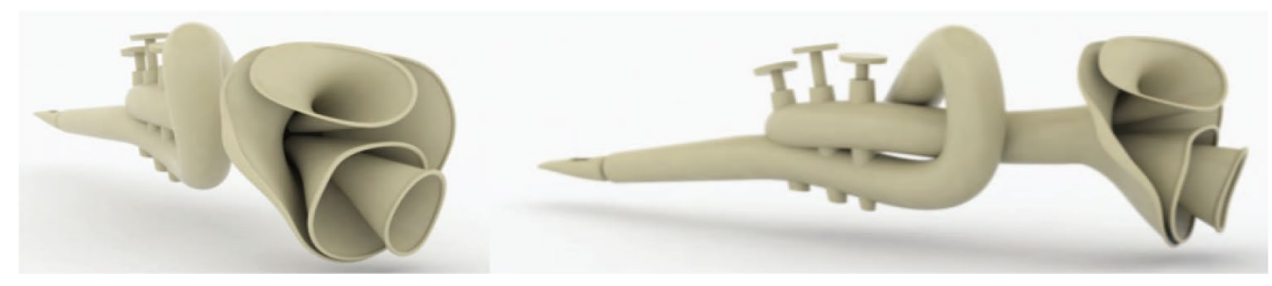
serves as the interface between the player and the instrument. In this regard mass personalization of the saxophone mouthpiece is already reported in [39].

With respect to saxophone mouthpiece, based on the functional requirements such as ease of blowing the mouthpiece (resistance), range of pitch alterations (flexibility) and sound characteristics (volume, brightness) personalization can be achieved. These functional requirements are correlated with the design variables of the mouthpiece like tip opening, chamber shape, throat shape, etc. They found that when the user makes a preference in the order of flexibility, sound characteristics, resistance; with the help of an algorithm, all the design variables of the personalized mouthpiece are built and an automatically generated 3D model is ready to be manufactured. In that study SLA technique is used to build the prototypes using Form Labs Form 2 printer and a translucent resin. SLA technique is preferred as the design variables of the mouthpiece considered to have sensitivity of $0.1 \mathrm{~mm}$.

In another study, trombone mouth pieces were designed, manufactured and statistically evaluated based on various end user requirements like sound quality, buying cost, customization and personal symbol, mouth and lips comfort, ease of storing the mouthpiece, loudness, etc. [17]. They have found that in comparison with a metallic mouthpiece, SLA-printed mouthpieces fared better design solutions. Among customization AM-mouthpieces outclass the traditional metal mouthpiece as it is possible to add distinct writings or distinctive features such as a pair of printed moustaches. It said that AM technologies look promising and superior to traditional manufacturing methods when personalization and economic issues are considered.

\subsubsection{Innovation}

On the innovation front, inspired instrument makers and enthusiastic individual players now have access to the fabrication method that is getting simpler and economic over time and allows them to turn their ideas into threedimensional physical objects [11]. There have been a number of suggested innovative applications like multipipe trumpet or multi acoustic chambers (Fig. 9) to influence the acoustic qualities of the instrument [20]. These wind instruments are presented as a proof concept to showcase the potential of AM as these types of instruments are difficult to conceive with traditional manufacturing.

Traditional materials for wind instruments like flutes, trumpets and horns are often represented by wood, bamboo and metals like brass, bronze, silver, nickel, platinum and gold. The applicability of metals for making complex geometrical shapes is often limited by its manufacturability and machinability. In a recent study [26], the prospects of titanium alloy (widely used in aerospace applications) have been investigated for wind instruments using EBM. The uniqueness of the titanium-AM flute is in the following properties: Innovative design, higher biocompatibility, significantly richer musical sound, high lifetime, hardness, easy design development and termite proof. Further the sound quality is not affected by changes in external temperature or humidity. Thus, AM permits not only design modifications using CAD tools but also a wide range of material flexibility to come up with innovative wind instruments.

\section{Future directions}

Finally, before applying these AM technologies, material degradation, safety, environmental impact and the endurance capabilities of the additive-manufactured instruments have to be further investigated [40]. The geometric tolerance and surface finish with respect to AM methods on the acoustic performance needs further analysis. Further, different AM methods and the variability of the materials have resulted in minor variations in the parts printed with the same code [28]. This aspect needs further investigation as wind instruments require airtight components. The ability to use composite materials combining both acoustic and mechanical properties in AM can be considered for future high-quality instruments. The capability of printing, wood-like materials and the development of electronic wind instruments using AM technology are not included in this review. More research on this aspect is required to ensure the reproduction of sound quality with that of traditional wood or bamboo.

The post-processing of the additive-manufactured instrument requires specific tools. Studies that illustrate the relation between the surface finish and the sound characteristics are sparse. At present, skilled labour is required for finishing operations of additive-manufactured parts to meet the desired player's satisfaction. Therefore, the hybridization of subtractive and additive techniques will be highly beneficial in musical instrument research and development [41]. New machines which combine both additive manufacturing and subtractive machining within the same platform could help in the design of high-quality instruments and parts, and provide opportunities for musical instrument design and manufacturing. As a possible alternative, postprocessing operations such as polishing with chemical treatments or electrochemical methods needs further research. 


\section{Concluding remarks}

A systematic literature review is presented to assess the potential of AM for musical wind instruments and the results are shown graphically. The different AM technologies, materials used, challenges, and applications of AM for wind instruments are illustrated with examples.

- AM has found extensive application to create conventional wind instruments with unique aesthetic designs.

- AM contributes to personalization with its capability to tune specific instrument design parameters for professional musicians and in the development of low-cost instruments for beginners.

- In the context of restoration/conservation, AM combined with advanced CAD technologies provides a method to fabricate fully functional replicas of wind instruments.

- AM could be a great asset to understand the fundamentals of sound production of wind instruments and can also be used as a tool for music learning and teaching.

In conclusion, the role AM is rapidly growing especially in the wind instruments and is also a promising research tool. The results presented in this study are not exempt from limitations. The present study is focused on the acoustic music instruments and the potential of AM in development of electronic music instruments is not included. The heterogeneous nature of literature references in the adopted study and the limited set of data show that further research in this area is required. The interpretation of the article contents is based on a subjective analysis adopted for classification of the literature. In order to address this issue, the authors have included all possible AM applications. Finally, this overview could serve as a starting point to further extend future analysis and research directions.

Acknowledgements The authors thank four anonymous reviewers for their valuable comments on the paper. The assistance of Prof. Gary Scavaone on the discussion of the paper is also acknowledged.

\section{Compliance with ethical standards}

Conflict of interest The author declares that they have no conflict of interest.

Open Access This article is licensed under a Creative Commons Attribution 4.0 International License, which permits use, sharing, adaptation, distribution and reproduction in any medium or format, as long as you give appropriate credit to the original author(s) and the source, provide a link to the Creative Commons licence, and indicate if changes were made. The images or other third party material in this article are included in the article's Creative Commons licence, unless indicated otherwise in a credit line to the material. If material is not included in the article's Creative Commons licence and your intended use is not permitted by statutory regulation or exceeds the permitted use, you will need to obtain permission directly from the copyright holder. To view a copy of this licence, visit http://creativecommons .org/licenses/by/4.0/.

\section{Appendix}

See in Table 3

Table 3 Search string used for Google Scholar database

\begin{tabular}{lll}
\hline Sl. No. & Search statement & Number of articles \\
\hline 1 & exp additive manufacturing & $1,360,000$ \\
2 & exp printing, three dimensional & $2,140,000$ \\
3 & exp musical instruments & $1,290,000$ \\
4 & exp wind instruments & $2,400,000$ \\
5 & exp mouthpieces & 32,800 \\
6 & exp flute & 311,000 \\
7 & 3 or 4 or 5 or 6 & 330,000 \\
8 & 2 and 7 & 140 \\
9 & 1 and 7 & 534 \\
10 & Limit 9 to (English language and year & 106 \\
& 2011-current) excluding duplicates \\
\hline
\end{tabular}

\section{References}

1. Ligon SC, Liska R, Stampfl J et al (2017) Polymers for 3D Printing and Customized Additive Manufacturing. Chem Rev 117:10212-10290. https://doi.org/10.1021/acs.chemrev.7b000 74

2. Ngo TD, Kashani A, Imbalzano G et al (2018) Additive manufacturing (3D printing): a review of materials, methods, applications and challenges. Compos Part B Eng 143:172-196. https ://doi.org/10.1016/j.compositesb.2018.02.012

3. Bikas H, Stavropoulos P, Chryssolouris G (2016) Additive manufacturing methods and modeling approaches: a critical review. Int J Adv Manuf Technol 83:389-405. https://doi. org/10.1007/s00170-015-7576-2

4. Stavropoulos $P$, Foteinopoulos $P$, Papacharalampopoulos $A$, Bikas $H$ (2018) Addressing the challenges for the industrial application of additive manufacturing: towards a hybrid solution. Int J Light Mater Manuf 1:157-168. https://doi. org/10.1016/j.ijlmm.2018.07.002

5. Calignano F, Manfredi D, Ambrosio EP et al (2017) Overview on additive manufacturing technologies. Proc IEEE 105:593-612. https://doi.org/10.1109/JPROC.2016.2625098

6. Thompson MK, Moroni G, Vaneker T et al (2016) Design for additive manufacturing: trends, opportunities, considerations, and constraints. CIRP Ann Manuf Technol 65:737-760. https:// doi.org/10.1016/j.cirp.2016.05.004 
7. Coon C, Pretzel B, Lomax T, Strlič M (2016) Preserving rapid prototypes: a review. Herit Sci 4:1-16. https://doi.org/10.1186/ s40494-016-0097-y

8. Kietzmann J, Pitt L, Berthon P (2015) Disruptions, decisions, and destinations: enter the age of 3-D printing and additive manufacturing. Bus Horiz 58:209-215. https://doi. org/10.1016/j.bushor.2014.11.005

9. Aita-Holmes C, Liacouras P, Wilson WO, Grant GT (2015) Digital capture, design, and manufacturing of an extraoral device for a clarinet player with Bell's palsy. J Prosthet Dent 114:297-300. https://doi.org/10.1016/j.prosdent.2015.02.029

10. Rayna T, Striukova L, Darlington J (2015) Co-creation and user innovation: the role of online 3D printing platforms. J Eng Technol Manag JET-M 37:90-102. https://doi.org/10.1016/j. jengtecman.2015.07.002

11. Kantaros A, Diegel O (2018) 3D printing technology in musical instrument research: reviewing the potential. Rapid Prototyp J 24:1511-1523. https://doi.org/10.1108/RPJ-05-2017-0095

12. Bucur V (2019) Digital fabrication of some wind instruments. In: Bucur V (ed) Handbook of materials for wind musical instruments. Springer Nature, Switzerland, pp 593-612

13. Fletcher NH, Rossing TD (1998) The physics of musical instruments, 2nd edn. Springer, Berlin

14. Lorenzoni V, Doubrovski Z, Verlinden JC (2013) Embracing the digital in instrument making: towards a musician-tailored mouthpiece by 3D printing. In: proceedings of the Stockholm musical acoustics conference 2013, SMAC 2013, Stockholm, Sweden

15. Doubrovski E, Verlinden J, Geraedts J et al (2012) Acoustic investigation of novel saxophone mouthpiece designs. In: Proceedings 9th international symposium on tools and methods of competitive engineering 2012, TMCE 2012, Karlsruhe, Germany

16. Spanou D (2019) A study on manufacturing and 3D printing of a mouthpiece for a classical alto saxophone. University of the Aegean

17. Bacciaglia A, Ceruti A, Liverani A (2019) Evaluation of 3D printed mouthpieces for musical instruments. Rapid Prototyp J. https:// doi.org/10.1108/RPJ-07-2019-0187

18. Bacciaglia A, Ceruti A, Liverani A (2019) A systematic review of voxelization method in additive manufacturing. Mech Ind. https ://doi.org/10.1051/meca/2019058

19. Gibson I, Rosen D, Stucker B (2015) Additive manufacturing technologies. Springer, New York

20. Zoran A (2011) The 3D printed flute: digital fabrication and design of musical instruments. J New Music Res 40:379-387. https://doi.org/10.1080/09298215.2011.621541

21. Makino M, Suzuki K, Takamatsu K et al (2018) 3D printing of police whistles for STEM education. Microsyst Technol 24:745748. https://doi.org/10.1007/s00542-017-3393-x

22. Marin B, Madrid García JA, Bachiller MC (2019) Conceptual model for the replacement of the horn of a nineteenth century phonograph. Stud Conserv 64:240-248. https://doi. org/10.1080/00393630.2018.1492273

23. Huang J, Chen $\mathrm{Q}$, Jiang $\mathrm{H}$ et al (2020) A survey of design methods for material extrusion polymer 3D printing. Virtual Phys Prototyp. https://doi.org/10.1080/17452759.2019.1708027

24. Bae EJ, Do JI, Kim WC, Kim JH (2017) A comparative study of additive and subtractive manufacturing for dental restorations. J Prosthet Dent 118:187-193. https://doi.org/10.1016/j.prosd ent.2016.11.004

25. Savan J, Simian R (2014) CAD modelling and 3D printing for musical instrument research: the renaissance cornett as a case study. Early Music 42:537-544. https://doi.org/10.1093/em/ cau090
26. Kolomiets A, Grobman YJ, Popov VV et al (2020) The titanium 3D-printed flute: new prospects of additive manufacturing for musical wind instruments design. J New Music Res. https://doi. org/10.1080/09298215.2020.1824240

27. Tumbleston JR, Shirvanyants D, Ermoshkin N et al (2015) Continuous liquid interface of 3D objects. Science 80(347):1349-1352

28. Cottrell S, Howell J (2019) Reproducing musical instrument components from manufacturers' technical drawings using 3D printing: Boosey \& Hawkes as a case study. J New Music Res 48:449-457. https://doi.org/10.1080/09298215.2019.1642362

29. Sugavaneswaran M, Arumaikkannu G (2014) Modelling for randomly oriented multi material additive manufacturing component and its fabrication. Mater Des 54:779-785. https://doi. org/10.1016/j.matdes.2013.08.102

30. Howe R, Shahbazmohamadi S, Bass R, Singh P (2014) Digital evaluation and replication of period wind instruments: the role of micro-computed tomography and additive manufacturing. Early Music 42:529-536. https://doi.org/10.1093/em/cau091

31. Celentano F, Dipasquale R, Simoneau E et al (2017) Reverse engineering and geometric optimization for resurrecting antique saxophone sound using micro-computed tomography and additive manufacturing. J Comput Inf Sci Eng 17:1-6. https:// doi.org/10.1115/1.4037180

32. Bellia A (2019) Towards a new approach in the study of ancient greek music: virtual reconstruction of an ancient musical instrument from Greek Sicily. Digit Scholarsh Humanit 34:233-243. https://doi.org/10.1093/llc/fqy043

33. Katz J (2017) Digitized maya music: the creation of a 3D database of Maya musical artifacts. Digit Appl Archaeol Cult Herit 6:29-37. https://doi.org/10.1016/j.daach.2017.08.004

34. Koumartzis N, Tzetzis D, Kyratsis P, Kotsakis RG (2015) A new music instrument from ancient times: modern reconstruction of the greek lyre of hermes using 3D laser scanning, advanced computer aided design and audio analysis. J New Music Res 44:324-346. https://doi.org/10.1080/09298215.2015.1106563

35. Umetani N, Panotopoulou A, Schmidt R, Whiting E (2016) Printone: interactive resonance simulation for free-form print-wind instrument design. ACM Trans Graph 35:1-14. https://doi. org/10.1145/2980179.2980250

36. Dabin M, Narushima T, Beirne S, et al (2016) 3D Modelling and printing of microtonal flutes. In: NIME 2016 proceedings of the international conference on new interfaces for musical expression. pp 286-290

37. Ritz C, Dabin M, Narushima T et al (2015) 3D printing for custom design and manufacture of microtonal flutes. SPIE Newsroom. https://doi.org/10.1117/2.1201508.006082

38. Avanzini F, Baratè A, Ludovico LA (2019) 3d printing in preschool music education: opportunities and challenges. Qwerty-Open Interdiscip J Technol Cult Educ 14:71-92

39. Ozdemir M, Cascini G (2020) An experiment-driven masspersonalisation model: application to saxophone mouthpiece production. Proc Des Soc Des Conf 1:1037-1046. https://doi. org/10.1017/dsd.2020.169

40. Oskui SM, Diamante G, Liao C et al (2016) Assessing and reducing the toxicity of 3D-Printed parts. Environ Sci Technol Lett 3:1-6. https://doi.org/10.1021/acs.estlett.5b00249

41. Cavdir D (2019) Digital manufacturing for musical applications : a survey of current and future outlook. Proceedings 16th international conference on sound and music computing 2019, SMC 2019, Malaga, Spain

Publisher's Note Springer Nature remains neutral with regard to jurisdictional claims in published maps and institutional affiliations. 